\title{
Haematological and Haemostatic Changes Associated with Major Depressive Disorder among Nigerians.
}

\author{
Oloruntoba A. Ekun ${ }^{1 *}$, Oluwatoyin T. Okunola ${ }^{2}$, Adeola O. Adebayo ${ }^{2}$, Adesola O. \\ Olalekan $^{1}$, Mojisola Oshikoya ${ }^{2}$, Aishat Shehu' ${ }^{2}$, Dotun Esan ${ }^{2}$, Mary F. Oshundun ${ }^{1}$ \\ ${ }^{I}$ Department of Medical Laboratory Science, College of Medicine, University of Lagos, Nige- \\ ria. \\ ${ }_{2}^{2}$ Medical Laboratory department Federal Neuro-Psychiatric Hospital Yaba, Lagos, Nigeria .
}

\begin{abstract}
*Correspondence should be addressed to Oloruntoba A. Ekun: oekun@unilag.edu.ng, ayodele1619.oe@gmail.com
Received 28th November 2020; Revised 25th January 2021; Accepted 30th January 2021

C) 2021 Ekun et al. Licensee Pan African Journal of Life Sciences an official publication of Faculty of Basic Medical Sciences, Ladoke Akintola University of Technology, Ogbomoso. This is an Open Access article distributed under the terms of the Creative commons Attribution License (https://creativecommons.org/licenses/BY/4.0), which permits unrestricted use, distribution, and reproduction in any medium, provided the original work is properly cited.
\end{abstract}

\section{Abstract}

Background: A link between major depressive disorder (MDD) and haematological as well as coagulation disorders has been postulated. This study aims to evaluate haematological and haemostatic changes among Nigerians with major depressive disorder

Methods: Two hundred volunteers consisting of an equal number of individuals diagnosed with major depressive disorder (MDD) based on DMS-IV criteria and apparently healthy control participated in this study. The blood sample was collected into tri-sodium citrate K2EDTA bottles respectively and was evaluated for some haemostatic parameters, using ELISA, Clauss, Quick's One Stage, Proctor and Rapaport's methods.

Results: The mean WBC, hemoglobin and differential lymphocyte were significantly higher among MDD total volunteers $(\mathrm{p}<0.001)$. The red cell indices and platelet count were lower among MDD ( $<$ 0.001). Also the prothrombin time (PT), fibrinogen, protein-C and erythrocytes sedimentation rate (ESR) were all raised $(\mathrm{p}<0.001)$ among volunteers with MDD. Positive associations existed between MCV and RBC (r: 0.364; p<0.001), PT and APTT (r: $0.319 \mathrm{p}<0.001$ ), APTT and fibrinogen (r: $0.239, \mathrm{p}=0.017)$ as well as PT and fibrinogen $(\mathrm{r}: 0.275 \mathrm{p}=0.006)$ at $95 \%$ confidence interval.

Conclusion: Changes in total leucocytes count, lymphocytes values and haemostatic parameters among volunteers with depression may impacts deleterious effects on the immune response as well as haemostatic homeostasis, while decreased red cell indices may suggest occult nutritional anaemia.

Keywords: Depression, haematological parameters, Red cell indices, Protein C, D-Dimer, Fibrinogen. 


\subsection{INTRODUCTION}

Major depressive disorder (MDD) has been described as a medical condition that primarily affects an individual's mood as well as behaviour [1]. Available data has suggested that affected individuals present with a myriad of features which constitute their dispositions to life in general $[2,3]$.

It has been suggested that major depressive disorder may be a risk factor for complications and death in individuals with ischaemic heart disease [IHD] [4, 5]. This disorder could also present in different forms [6].

Furthermore, some haematological disorders may be seen in individuals with depressive disorder. While there are few data that demonstrated the negative impact of depression on coagulation derangements [7-9], there is a paucity of similar studies among Nigerians with depressive illness. Thus this study is set to further build on the previous studies with particular reference to Nigerian depressive disorders volunteers.

It appears that the relationship between Major depressive disorder and haematological changes has not been extensively studied. However, there was a previous study that evaluated some hematology indices in manic depressive disorder [10].

The previous study has opined that major depressive disorder and anxiety tend to be closely related, as the genes coding for the symptoms of MDD possibly influences the symptoms of anxiety [11].

It has been shown in some previous studies that most Major depressive disorder and anxiety disorders might manifest early in life in affected individuals [11-13]; while available data suggested that MDD that manifests later in adulthood might have resulted from specific and different etiological factors [14-17].

\subsection{METHODOLOGY}

\subsection{Study Design and Location}

This is a cross sectional study carried out over a period of six months. The study was carried out at the Federal Neuro-psychiatric, Yaba, Lagos State, Nigeria.

\subsection{Study Population}

Participants for this study were randomly recruited from the outpatient of the Federal Neuro-psychiatric Hospital,
Yaba, Lagos State. A total of two hundred volunteers, participated in this study. The test participants (case) consist of $100 \mathrm{MDD}$ [6] patients while the control group consists of 100 age-matched apparently healthy volunteers. MDD patients recruited was based on DMS IV criteria. Participants were randomly selected and prevalence of $3.1 \%$ (lifetime) and $1.1 \%$ (12-months) based on population-based world mental health survey initiative in Nigeria [18]. Participants recruited were those who have been diagnosed of MDD and have been receiving treatment for at least six months.

Information on socio-economic and demographic status of participants was taken through questionnaire design for the study.

\subsection{Ethical Considerations, Inclusion and Exclusion Criteria}

Approval for this study was obtained from the ethics and research committee of the Federal Neuro-Psychiatric Hospital, Yaba Lagos Nigeria [FNPHY/ERC/14/102]. This study was conducted in the same hospital. Thus participants consent was sought and obtained before they were enrolled for this study.

Participants (male and female) with depression aged 30 to 70 as well as apparently healthy age matched individuals which served as control were included.

Those excluded are individuals below 30 years of age and above 70 years. Also individuals with any other form of ailment(s) apart from depression were excluded from this study.

\subsection{Laboratory Methods}

Collection of Blood Samples: Blood sample was collected from each participant into sodium citrate and K2EDTA bottles respectively. The samples were used for the haematological studies respectively.

The Erythrocyte sedimentation rate was determined using Westergren method [19]. This method involve the usin of Dispette 2 Citrate (GS-1650) manufactured by Guest Scientific AG. Activated Partial Thromboplastin Time was determined by Proctor and Rapaport's modification method [20] using commercially prepared Kaolin Platelet Substitute Mixture manufactured by Diagnostic Reagents Ltd. Fibrinogen Estimation was carried out based on Clauss method [21] using Fibrinogen Determination Kit manufactured by Diagnostic Reagents Ltd. Prothrombin time test was 
determined using Quick's One Stage method [22]. Protein $\mathrm{C}$ and D-dimer were determined using ELISA method [23]. Full Blood Count was determined based on Coulter's principle [24-26].

\subsection{Statistical/Data Analysis}

Data were analyzed using SPSS version 20 statistical packages. Descriptive statistics of mean \pm SEM was used to examine the data. Independent student's t- test was used to compare groups. Pearson correlation analysis was conducted to evaluate the degree of association of the parameters studied. The probability value of $p<0.05$ was considered significant for this study.

\subsection{RESULTS}

The mean age of the participants were $47.0 \pm 1.23$ and $48.1 \pm 0.97$ years for test and control respectively. Age group 30-40 had more volunteers with depression (39\%) of all the age ranges while age group 61-70 had the least (17\%). In the overall, $53 \%$ and $47 \%$ represented the percentage of male and female volunteers respectively with depression in this study.

The mean white blood cell and red blood cell counts were significantly $(\mathrm{P}<0.05)$ higher among MDD participants. On the other hand mean haemoglobin, platelet and red cell indices were lower $(p<0.05)$ in MDD patients

\subsection{Haemostatic Parameters}

The prothrombin time test, protein $\mathrm{C}$, Fibrinogen and erythrocytes sedimentation rate in MDD were higher $(\mathrm{p}<0.05)$ than control.

\subsection{Pearson Correlation Studies}

The degree of association between continuous variables were evaluated. There was a positive association $(\mathrm{p}<0.05)$ between MCV and RBC, Monocytes and platelets and between PT and APTT, PT and Fibrinogen among patients with major depressive disorder .

\subsection{DISCUSSION}

Depressive disorders are significant medical disorders which are associated with psychiatric symptoms [27]. It is characterized by disruption in mood as well as the behaviour of the affected individuals [1]. In this study, we evaluated some haematological, and hemostatic parame- ters among volunteers who have been diagnosed with the major depressive disorder using defined standard procedures [6]. The mean age (table 1) of the test volunteers was not different from the control. This was expected as the study design was to study age matched case and control participants with a view to nolify any possible impact of diversity in age of the study population. A previous study, by Sebastian [28] suggested that ageing may be a possible risk factor for depression. While some changes are normal with ageing, a study has shown that depression is not a function of ageing. It is instructive to note that ages 31-40 had the highest number of volunteers with the depressive disease (figure 1). This observation may suggest the possible increased burden ranging from economic, societal, family and marital burden on the younger age generations in Nigeria. It is also good to note that 53 and 47 test participants representing 53\% and $47 \%$ were male and female respectively (figure 2). This observation suggests that both sexes are affected by depression among Nigerian population. However, in this study, the male participants were slightly more affected than the female (figure 2). Previous studies have suggested that in most cases, depressive illness and anxiety disorder occur early in life [11-13]. Available data have also opined that genetic and environmental factors may play key roles in the development of depressive and anxiety illnesses [11-13]. In this study, however, it was observed that the incidence of depression appears to be higher among young adults age 30 to 40; thus agreeing with the previous studies by Kendler et al.,[11], Kendler et al., [12], and Kendler et al., [13]. It thus appears that ageing may not be a major risk factor for depressive illness.

We observed that the test group had a significantly higher total white blood cell count and lymphocyte differential counts when compared with the control. The white blood cells play a cardinal role in human's immunological response. An increase in total white blood cell count, as well as lymphocytes, differential count among individuals with major depressive disorder when compared to the apparently healthy control could suggest that depression may affect the immunological response in affected individuals. This is because the white blood cells particularly the lymphocytes cells are critical in cell mediated immune responses in humans. Thus whatever affects these cells may indirectly impact on the immune response of an individuals. Available data on the effect of depression on immunological response and immunologi- 


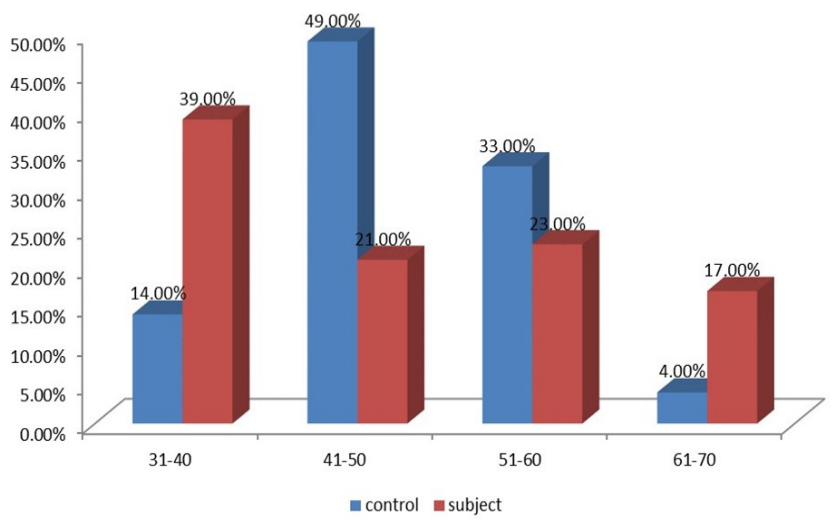

Figure 1. showing the age distribution of the participants

Table 1. Haematological Descriptive Statistics for both Test and Control Group .

\begin{tabular}{|c|c|c|c|c|}
\hline $\begin{array}{l}\text { Variables } \\
\mathrm{n}=100\end{array}$ & $\begin{array}{l}\text { Test group } \\
\text { Mean } \pm \text { SEM }\end{array}$ & $\begin{array}{l}\text { Control } \\
\text { group } \\
\text { Mean } \pm \text { SEM }\end{array}$ & t-test & p value \\
\hline $\operatorname{Age}(y r)$ & $47.0 \pm 1.23$ & $48.1 \pm 0.97$ & 0.539 & 0.446 \\
\hline WBC & $5.5 \pm 0.15$ & $4.6 \pm 0.10$ & 4.583 & $<0.05^{*}$ \\
\hline $\begin{array}{l}\left(\times 10^{9} / \mathrm{L}\right) \\
\mathrm{RBC}\end{array}$ & $4.5 \pm 0.05$ & $4.1 \pm 0.07$ & 4.433 & $<0.05^{*}$ \\
\hline $\begin{array}{l}\left(\times 10^{12} / \mathrm{L}\right) \\
\mathrm{HB}(\mathrm{g} / \mathrm{dl})\end{array}$ & $11.9 \pm 0.13$ & $13.78 \pm 2.34$ & -5.397 & $<0.05^{*}$ \\
\hline $\mathrm{PCV}(\mathrm{L} / \mathrm{L})$ & $0.4 \pm 0.01$ & $0.4 \pm 0.01$ & 0.306 & 0.760 \\
\hline $\operatorname{PLT}\left(\times 10^{9} /\right.$ & $163.3 \pm 4.78$ & $205.0 \pm 7.22$ & -4.378 & $<0.05^{*}$ \\
\hline $\begin{array}{l}\mathrm{L}) \\
\mathrm{MCH}\end{array}$ & $25.8 \pm 0.25$ & $33.8 \pm 0.60$ & -12.137 & $<0.05^{*}$ \\
\hline$(\mathrm{pg})$ & & & & \\
\hline $\operatorname{MCV}(\mathrm{fl})$ & $82.5 \pm 5.58$ & $90.1 \pm 1.30$ & -5.294 & $<0.05^{*}$ \\
\hline $\begin{array}{l}\mathrm{MCHC} \\
(\mathrm{g} / \mathrm{L})\end{array}$ & $312.0 \pm 0.15$ & $370.9 \pm 2.14$ & -1.5791 & $<0.05^{*}$ \\
\hline NEU(\%) & $48.4 \pm 1.21$ & $48.3 \pm 0.10$ & 0.058 & 0.954 \\
\hline LYM & $48.2 \pm 1.15$ & $42.6 \pm 0.94$ & 3.543 & $<0.05^{*}$ \\
\hline $\begin{array}{l}(\%) \\
\text { MON }\end{array}$ & $2.6 \pm 0.33$ & $7.1 \pm 0.15$ & -11.699 & $<0.05^{*}$ \\
\hline $\begin{array}{l}(\%) \\
\operatorname{EOS}(\%)\end{array}$ & $1.0 \pm 0.17$ & $1.9 \pm 0.28$ & -2.726 & $<0.05^{*}$ \\
\hline $\begin{array}{l}\text { BASO } \\
(\%) \\
\end{array}$ & $0.0 \pm 0.00$ & $0.1 \pm 0.03$ & -2.935 & $0.004 *$ \\
\hline
\end{tabular}

WBC - White Blood Cell, RBC - Red Blood Cell, HGB -Haemoglobin Concentration, HCT - Haematocrit, MCV - Mean Cell Volume, MCH - Mean Corpuscular Haemoglobin, PLT - Platelet, MCHC - Mean Corpuscular Haemoglobin Concentration, NEUTNeutrophils, LYM-Lymphocytes, MON-Monocyte, EOS-Eosinophils, BAS-Basophils, *significant $\mathrm{p}$ value $(\mathrm{p}<0.05)$.

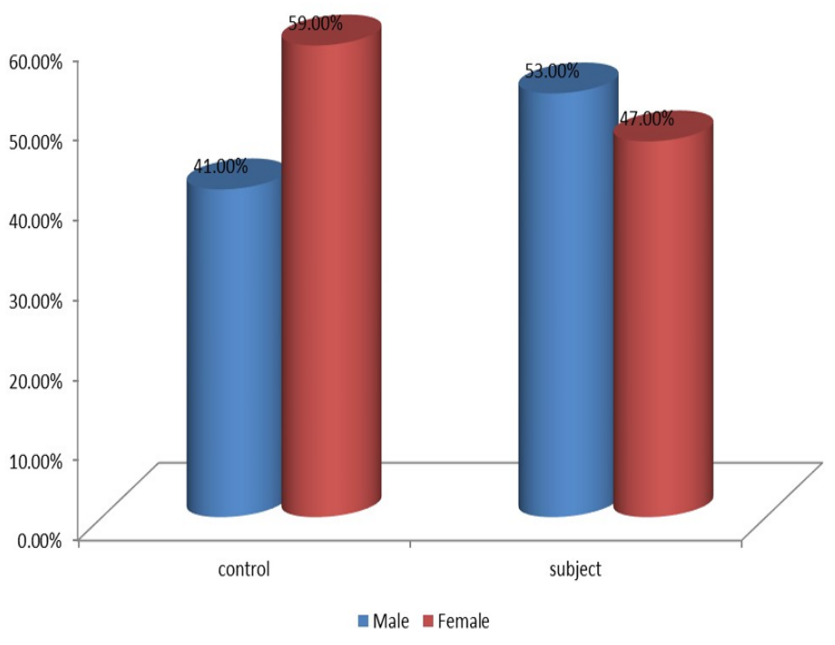

Figure 2. Showing the Distribution of test and Control

Table 2. Evaluation of degree of association among the parameters evaluated.

\begin{tabular}{lll}
\hline Variable & $\begin{array}{l}\text { Correlation Coef- } \\
\text { ficient (r) }\end{array}$ & P (value) \\
\hline $\begin{array}{l}\text { Red blood cell } \\
\text { and Packed Cell }\end{array}$ & 0.825 & $<0.001^{*}$ \\
$\begin{array}{l}\text { Volume } \\
\text { Hemoglobin and }\end{array}$ & 0.980 & $<0.001^{*}$ \\
$\begin{array}{l}\text { Packed Cell Vol- } \\
\text { ume }\end{array}$ & & $<0.001^{*}$ \\
$\begin{array}{l}\text { Mean Cell Vol- } \\
\text { ume and Red }\end{array}$ & 0.364 & \\
$\begin{array}{l}\text { Blood Cells } \\
\text { Neutrophil and }\end{array}$ & -0.944 & $<0.001^{*}$ \\
$\begin{array}{l}\text { Lymphocytes } \\
\text { Monocyte and }\end{array}$ & -0.379 & $<0.001^{*}$ \\
$\begin{array}{l}\text { Neutrophil } \\
\text { Monocyte and }\end{array}$ & 0.229 & $0.022^{*}$ \\
$\begin{array}{l}\text { Platelet } \\
\text { Prothrombin and }\end{array}$ & 0.319 & $<0.001^{*}$ \\
$\begin{array}{l}\text { APTT } \\
\text { PT and FIB }\end{array}$ & 0.275 & $0.006^{*}$ \\
APTT and FIB & 0.239 & $0.017^{*}$ \\
$\begin{array}{l}\text { Protein-C and D- } \\
\text { dimer }\end{array}$ & 0.045 & 0.656 \\
Protein-C and & 0.103 & 0.309 \\
\hline ESR
\end{tabular}

PCV - Packed Cell volume, RBC - Red Blood Cell, HGB - Haemoglobin Concentration, MCV - Mean Cell Volume, NEUT- Neutrophils, LYMLymphocytes, MON- Monocyte, EOS- Eosinophils, BAS- Basophils, PTProthrombin Time, APTT- Activated Partial Thromboplastin Time, FIBFibrinogen Concentration, ESR- Erythrocyte Sedimentation Rate

cal dysfunction has been inconsistent [29]. Some of the possible reasons for these inconsistent observations might be due to the etiological variability of depression [29]. 


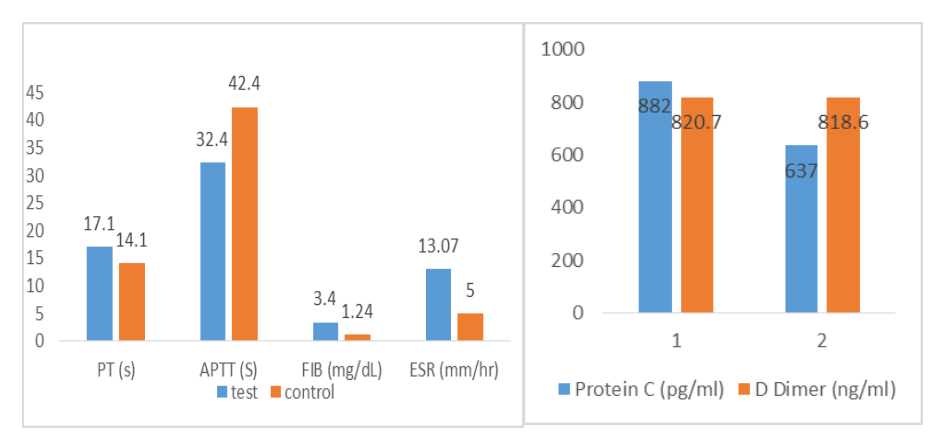

Figure 3a and 3b. Coagulation and Inhibitor of Coagulation Profile among the Participants.

PT-Prothrombin Time, APTT-Activated Partial Thromboplastin Time, FIB-Fibrinogen Concentration, ESR-Erythrocyte Sedimentation Rate

However, a previous study showed that alteration in mood control aspect of nervous system possibly impacts deleterious effects on the immunological integrity of the affected individuals [30]. This by extension may impact negatively on the behaviour of the affected individuals [30]. Thus a significant increase in the lymphocytes differential count may suggest that depressive disorders could modulate the immunological responses of the affected persons.

In addition to this, the mean Prothrombin time and Fibrinogen were significantly higher (Figure $3 \mathrm{a}$ ) among volunteers with depressive illness when compared with the control group, whereas the mean APTT was observed to be lower $(\mathrm{p}<0.05)$ among the MDD volunteers. A prolonged prothrombin time in the presence of normal APTT may suggest a possible factor VII deficiency [31] among volunteers with depressive illness. This study agrees with the previous study by Canan et al., [7], who observed a link between depression and some haematological disorders. It could also probably means that there may be a possible relationship between deficiency of factor VII and increase in some natural inhibitors of coagulation such as protein C. The outcome of this study possibly corroborate a previous study by Geiser et al., [9] who reported that abnormal coagulation proteins activations, particularly in depressive patients on medication, exist, leading to abnormal plasma fibrinogen and fibrinolytic activities; however, the mechanism for this abnormal activation is not fully elucidated. It is worthy of note that the volunteers with depressive illness demonstrated a significant increase in the mean fibrinogen level (Figure 3a). This observation in particular seems to be in consonance with the previous observations from the studies by Geiser et al., [9], Panagiotakes et al., [32] and Wiun-Anderson et al., [33] demonstrated an increase in plasma fibrinogen among individuals with depression. This could also be associated with some degree of inflammation as demonstrated by an increase in the mean erythrocytes sedimentation rate among individuals with major depressive disorder (Figure 3a).

In this study, we observed an increase $(p<0.05)$ in the mean Protein-C concentration among volunteers with depressive illness. While protein $\mathrm{C}$ activation from its inactive zymogen to active protease involves cleavage by thrombin at the Arg169-Leu170 peptide bond, this cleavage is accelerated by thrombomodulin and endothelial protein C receptor (EPCR) [34-37]. However, the mechanism of activated protein C (APC'S) direct anticoagulant activity involve factors $\mathrm{V}$ and $\mathrm{VIII}$ which are homologous coagulation cofactors that circulate in inactive molecules; these are converted to active cofactors by limited proteolysis. Irreversible proteolytic inactivation of factors $\mathrm{Va}$ and VIIIa by APC results in its anticoagulant activities. An increase mean value of protein $C$ in this study, however, did not lead to an increase in the mean APTT level of depressive illness volunteers as one would have thought. The reason for this observation is sparse; however, the effect of drugs and other depression factors may play a role. On the other hand, the D-Dimer value among test and control groups did not vary significantly (Figure $3 b)$.

An increase in the mean erythrocyte sedimentation rate as observed among the depressive illness group suggests that this disorder may have a link with inflammation. Previous studies have however suggested a link between inflammation and depressive illness. Available data suggested that depression is associated with a higher concentration of some inflammatory cytokines [38-40]. Krishnadas and Cavanagh [39] however reported that in some predisposed individuals, stress could induce proinflammatory cytokine release which in-turn stimulates the release of extrahepatic enzyme Indoleamine 2, 3 dioxygenase (IDO). Thus enhanced IDO pathways possibly lead to a reduction in serotonin availability and increase in glutamate receptor activation as a result of metabolism of kynurenine into quinolinic acid. This acid has been observed to enhance glutamatergic receptors [41].Thus a deficiency in serotonin availability coupled with glutamatergic overdrive in proinflammatory states gives rise towards a likely depressive syndrome [40]. 
In addition to this, we observed that a decrease in the mean values of $\mathrm{MCV}, \mathrm{MCH}$ and $\mathrm{MCHC}$ occurred among volunteers with depression. Decrease in red cell indices as observed in this study may be an indication of occult nutritional deficiencies among volunteers with major depressive disease investigated in this study. Our observation possibly supports previous studies that suggested a possible correlation between nutritional deficiencies and risk of some neuropsychiatric disorders [42-47]. Previous study has suggested a relationship between low omega-3 fatty acids consumption and the risk of incidence of major depression [42]. Other study has previously linked vitamin $\mathrm{B}$, folate and magnesium deficiencies to depression [48, 49].

Moreover an evaluation of degrees of association between the various parameters studied showed a positive and significant association between haemoglobin and packed cell volume, haemoglobin and $\mathrm{RBC}, \mathrm{MCV}$ and RBC, Lymphocytes and Monocytes, PT and APTT, PT and FIB APTT and FIB. On the other hand, a negative and significant association was observed between lymphocytes and monocytes, as well as between neutrophils and monocytes. Positive but insignificant associations were observed between Erythrocyte's sedimentation rate. \& Protein-C, D-dimer and ESR, and between protein-C and Ddimer. It must be noted that a positive and significant association suggest a direct relationship between the parameters involved whereas a positive and insignificant relationship may suggest the absence of any dependency on the parameters involved. An inverse relationship between the parameters measured suggests that an increase in a particular parameter may leads to decrease in the other parameter. Thus in this study, an increase in prothrombin time test value was also associated with increase in fibrinogen level; suggesting that increase in PT may triggers inflammatory response thus leading to elevated fibrinogen and erythrocytes sedimentation rate values.

The outcome of this study shows major depressive disorder may manifest some degree of inflammation as well as occult nutritional anaemia as demonstrated by elevated values of markers of inflammation (Erythrocytes sedimentation rate, Fibrinogen) and decrease in red cell indices (Mean cell volume (MCV), mean corpuscular haemoglobin concentration (MCHC), and mean cell haemoglobin $(\mathrm{MCH})$. There is an elevation in the plasma level of natural inhibitor of coagulation (Protein C) among individuals with major depressive disorder.
Limitation of this Study: this study was limited to haematological and haemostatic parameters in major depressive disorder. The biochemical evaluation was not investigated.

Acknowledgement: authors are grateful to the nurses and doctors of the Federal Neuro-Psychiatric Hospital Yaba, Lagos for their assistance during the course of this study.

Conflict of Interest: The authors declare that there is no conflict of interest regarding the publication of this paper

\section{Authors' Contribution}

OAE conceived and designed the study, contributed to data analysis tools, data analysis and manuscript writing. OTO, AAA contributed to data analysis tools, data analysis and manuscript writing. AOO contributed to data collection and data analysis tools MO, AS, DE contributed to collection of data, data analysis tools and analysis of data. MFO contributed to data analysis tools and analysis of data. All authors approved the final version of the manuscript

\section{References}

1. Salmans, S. Depression: Questions You Have - Answers You Need. People's Medical Society. 1997.

2. Schmidt P. Mood, Depression, and Reproductive Hormones in the Menopausal Transition. The American Journal of Medicine. 2005. 12: 54-8.

3. Cassano P, Fava M. Depression and public health: an overview. J Psychosom Res. 2002. 53:849-857.

4. Bush DE, Ziegelstein RC, Tayback M, Richter D, Stevens $\mathrm{S}$, Zahalsky $\mathrm{H}$ et al. Even minimal symptoms of depression increase mortality risk after acute myocardial infarction. American Journal of Cardiology. 2001; 88:337-341.

5. Barefoot JC, Schroll M. Symptoms of depression, acute myocardial infarction, and total mortality in a community sample. Circulation. 1996. 93:1976

6. Diagnostic and Statistical Manual of Mental Disorders. Fourth edition, text revision. http:// dsm.psychiatryonline.org/doi/abs/10.1176/ appi.books.9780890420249.dsmiv-tr; 2000.

7. Canan F, Dikici S, Kutlucan A, Celbek G, Coskun H, Gungor A, et al., Association of mean Platelet volume with DSM-IV major depression in a large community-based population: The MELEN study. Journal of Psychiatric re- 
search. 2012. 46(3): 298-302.

8. Geiser F, Gessler K, Conrad R, mbierowicz K, Albus C, Harbrecht U. Can activation of coagulation and impairment of fibrinolysis in patients with anxiety and depression be reversed after improvement of psychiatric symptoms? Results of a pilot study. J Nerv Ment Dis. 2012. 200:721-3.

9. Geiser F, Conrad R, Imbierowicz K, Meier C, Liedtke R, Klingmüller D et al., Coagulation activation and fibrinolysis impairment are reduced in patients with anxiety and depression when medicated with serotonergic antidepressants. Psychiatry and Clinical Neurosciences. 2011. 65: $518-525$

10. Kaplan and Sadock's. Mood disorders: treatment of bipolar disorders in: Sadock BJ, Sadock VA, (eds). Chpt 14, Synopsis of Psychiatry, 10th edition. 1997; Depress Anxiety. 5: 202.

11. Kendler KS, Heath AC, Martin NG, Eaves LJ. Symptoms of anxiety and symptoms of depression. Same genes, different environments? Archives of General Psychiatry. 1987. 44:451-457.

12. Kendler KS, Heath A, Martin NG, Eaves LJ. Symptoms of anxiety and depression in a volunteer twin population. The etiologic role of genetic and environmental factors. Archives of General Psychiatry. 1986. 43: 213-221.

13. Kendler KS, Neale MC, Kessler RC, Heath AC, Eaves LJ. Major depression and generalized anxiety disorder. Same genes, (partly) different environments? Archives of General Psychiatry. 1992. 49:716-722.

14. Brodaty H, Luscombe G, Parker G, Wilhelm K, Hickie I, Austin MP, Mitchell P. Increased rate of psychosis and psychomotor change in depression with age. Psychological Medicine. 1997. 27:1205-1213.

15. Henderson AS. Does ageing protect against depression? Social Psychiatry and Psychiatric Epidemiology. 1994;.29:107-109.

16. Tupler LA, Krishnan KR, McDonald WM, Dombeck CB, D'Souza S, Steffens DC. Anatomic location and laterality of MRI signal hyper-intensities in late-life depression. Journal of Psychosomatic Research. 2002. 53: 665-676.

17. Krishnman KR, Biological risk factors in late life depression Biological Psychiatry. 2002. 52:185-192.

18. Gureje O, Uwakwe R, Oladeji B, makanjuola VO, Esan O. Depression in adult Nigerians: Results from the Nigerian survey of mental hhealth and well-being. J Affect Disord. 2010; 120:158-64.
19. Baker FJ, Silverton RE, Pallister CJ. Introduction to Medical Laboratory Technology. 2007. 7th ed. Bounty press.

20. Proctor RR, Rapaport SI. The partial thromboplastin time with kaolin. A simple screening test for first stage plasma clotting factor deficiencies. Am J Clin Pathol. 1961. $36: 212-9$.

21. Quick A J. The prothrombin in hemophilia and in obstructive jaundice. J. biol. Chem. 1935. 109: 73-4

22. Engvall, E., and Perlmann, P. Enzyme linked immunosorbent assay (ELISA). III. Quantitation of specific antibodies by enzyme-labelled anti-immunoglobulin in antigen coated tubes. J. Immunol. 1972. 109: 129-135.

23. Hogg WR, Coulter W. Apparatus and method for measuring a dividing particle size of a particulate system; United States Patent 3557352

24. DeBlois RW, Bean CP. (1970). "Counting and sizing of submicron particles by the resistive pulse technique". Review of Scientific Instruments.1970. 41(7): 909-916.

25. Marshall Don. Graham. "The Coulter Principle: Foundation of an Industry". Journal of Laboratory Automation.2003. 8(6): 72-81.

26. Varghese D, Scott J, Welham J, Bor W, Najman J, O’Callaghan M. et al., Psychotic-like experiences in major depression and anxiety disorders: a population-based survey in young adults. Schizophr Bull.2011. 37: 389-93.

27. Sebastian L. Ageing risk for depression. Perspectives In psychiatric care. 1995. 31:3:3-36.

28. Maes M. Evidence for an immune response in major depression: a review and hypothesis. Prog Neuropsychopharmacol Biol Psychiatry. 1995. 19(1):11-38.

29. Leonard BE. The immune system, depression and the action of antidepressants. Prog Neuropsychopharmacol Biol Psychiatry. 2001; 25(4):767-780.

30. Seligsohn U, Kaushansky K. Classification, clinical manifestations and evaluation of disorders of haemostasis in: Kenneth Kaushansky, Marshall A Lichtman, Ernest Beutler, Thomas J Kipps, Uri Seligsohn, Josef T. Prchall, editors. Medical William's Haematology, McGraw Hill. 2010; pg: 1883-1889

31. Panagiotakos DB, Pitsavos C, Chrysohoou C, Tsetsekou E, Papageorgiou C, Christodoulou G, et al., Inflammation, coagulation, and depressive symptomatology in cardiovascular disease-free people; the ATTICA study. Eur Heart J. 2004. 25:492-499. 
32. Wium-Andersen MK, Orsted DD, Nordestgaard BG. Elevated plasma fibrinogen, psychological distress, antidepressant use, and hospitalization with depression: Two large population-based studies. Psychoneuroendocrinology. 2012. 38:638-647.

33. Van de Wouwer M, Collen D, Con Way EM. Thrombomodulin-Protein C-EPCR system integrated to regulate coagulation and inflammation. Arterioscler Thromb Vasc Biol. 2004; 24:

34. Griffin JH. The thrombin Paradox. Nature. 1995; 378:337.

35. Esmon CT, Owen WG. The discovery of thrombomodulin. J thromb Haemost. 2004; 2:209.

36. Esmon CT. The role of Protein $\mathrm{C}$ and thrombomodulin in the regulation of blood coagulation. J Biol Chem.1989. $264: 4743$

37. Dowlati Y, Herrmann N, Swardfager W, Liu H, Sham L, Reim EK et al., A meta-analysis of cytokines in major depression. Biol Psychiatry. 2010. 67(5):446-457.

38. Krishnadas R, Cavanagh J. Depression: an inflammatory illness? J Neurol Neurosurg Psychiatry. 2012. 83(5):495502.

39. Almond M. Depression and inflammation examining the link. Current. Current Psychiatry. 2013. 12(6)25-32.

40. Müller N, Schwarz MJ. The immune-mediated alteration of serotonin and glutamate: towards an integrated view of depression. Mol Psychiatry. 2007. 12(11):988-1000.

41. Janicak PG, Lipinski J, Davis JM, Comaty JE, Waternaux
C, Cohen B et al., S-adenosylmethionine in depression: A literature Review and preliminary report. Ala J Med Sci. 1988. 25:306-13.

42. Adams PB, Lawson S, Sanigorski A, Sinclair AJ. Arachidonic acid to eicosapentaenoic acid ratio in blood correlates positively with clinical symptoms of depression. Lipids.1996. 31:S157-61.

43. Eby GA, Eby KL. Rapid recovery from major depression using magnesium treatment. Med Hypotheses. 2006. 67:362-70.

44. Wurtman R, O’Rourke D, Wurtman JJ. Nutrient imbalances in depressive disorders: Possible brain mechanism. Ann NY Acad Sci. 1989; 575:75-82.

45. Chouinard G, Young SN, Annable L. A controlled clinical trial of L-trytophan in acute mania. Biol Psychiatry.1985; 20:546-7.

46. Reis LC, Hibbelin JR. Cultural symbolism of fish and the psychotropic properties of omega-3 fatty acids. Postaglandin Leukot Essent Fatty Acids.2006; 75:227-36.

47. Grubb BP. Hypervitaminosis A following long-term use of high-dose fish oil supplements. Chest. 1990. 97:1260

48. Young SN. Folate and depression: a neglected problem. J Psychiatry Neurosci. 2007. 32:80-82.

49. Bell IR, Edman JS, Marrow FD, Marby DW, Mirages S, Perrone G, et al., B complex vitamin patterns in geriatric and young adult in-patients with major depression. J Am Geriatri Soc.1991. 39:252-7. 